\title{
Studies on the Water Metabolism in Diabetes Mellitus.
}

By

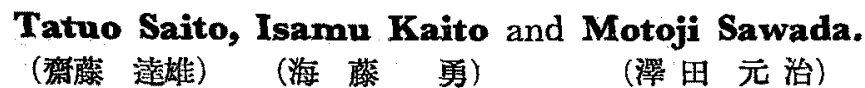

(From the Medical Clinic of Prof. T. Kurokawa, Tohoku University, Sendai.)

(Received for publication, February 17, 1948)

Polyuria is a chief complication of diabetes mellitus, and it is well known that from the excessive loss of water there results a severe degree of desiccation of the skin.

Jaksch ${ }^{1)}$ who in 1893 first reported a failure of water metabolism in diabetes, pointed out the loss of water and the increase of desiccated substance of the blood; afterwards Klein ${ }^{2)}$ and $\mathrm{Hoff}^{3)}$ also noticed the similar result.

On the other hand, there were many reseachers ${ }^{3-10}$ ) who reported the occurence of edema in diabetes mellitus. Moreover, we find many reports of the relationship between insulin and water metabolism; and it is generally accepted there is a definite water retention or restricted diuresis with the injection of insulin and so called " insulin edema." 2)11112)1314)

Further Meyer-Bisch ${ }^{15)}$ and others have reported of the water and mineral metabolism.

The following two methods have been generally accepted for the observation of the water metabolism in diabetes.

One is the observation of the blood concentration by means of hemoglobin determination and so on.2111)13/16)17)18)

The other is the measurement of output and specific gravity of urine after the administration of water. For example, Klein ${ }^{16)}$ and Gerbi ${ }^{19}$ ) pointed out by Volhard's water test that the urine output is less in diabetic cases before treatment than in normal persons. Ralli and others ${ }^{20}$ mentioned that in 8 cases of diabetic coma the amount of urine was very small in comparison with that of water taken.

In the present report we want to observe the water metabolism in diabetic patients, etiology of polyuria, the desiccation of the skin and edema.

\section{Materials and Method.}

Classification of diabetics in our Clinic is as follows: Type I which is 
recovered with " high carbohydrate, low fat diet," Type II with application of insulin.

Cases which are brought to our attention are 5 cases of Type I, 14 cases of Type II and 5 normal persons as the control.

Usually the experiments begin early in the morning prior to breakfast. During the experiments no foods are given.

"Volhard's dilution test" is performed for the first 4 hours by intake of 1000 c.c. of water from the mouth and without interruption we enter the "concentration test" for the last 4 hours by giving 200 grms. of bread. After the administration, urine was taken $\frac{1}{2}, 1,1 \frac{1}{2}, 2,3$ and 4 hours in the former test, $\frac{1}{2}, 1,2$ and 4 hours in the latter, and its quantity, specific gravity, urine sugar and in some cases blood sugar were examined.

They were weighed prior to and 4 hours after the water intake;

The blood sugar was determined by the Fujita-Iwatake's method, the urine sugar by the Bertrand.

\section{Results of Experiment.}

We well summarized the results of experiment performed in normal individuals and diabetic patients in Table $I$, most of the latter were experimented before, but partially soon after, dietary management.

From the results of the control experiment performed in 5 healthy persons, we observed that the total amount of urine during the first 4 hours was 985 to 1223 c.c., and during the last 4 hours was 120 to 490 c.c.

For example, in Case 1, after taking water an increased urine output reached its maximum and specific gravity its minimum in $1 \frac{1}{2}$ to 2 hours, followed by a gradual recovery. After taking bread there was no marked increase of the urine output, however the specific gravity reached its maximum in $\frac{1}{2}$ to 1 hour and no remarkable drop was detected.

2 cases gained, 2 cases lost in weight and 1 case remained unchanged.

We found no marked difference between the results of control experiment and those of Type I, showing that the amount of urine during the first 4 hours was 960 to 1490 c.c. and during the last was 133 to 505 c.c. During the former no urine sugar was found except in Case 8, although during the latter it was found in all cases.

Weight: 3 patients lost, 2 patients remained constant and no patient gained in weight.

In other all cases of Type II with the exception of 2 cases (Cases 11 and 12) in which we found more output than in normal persons and the loss of weight, it was interesting to note that after drinking water the amount of urine during 4 hours was very small, ranging from 120 to 780 c.c. and after eating bread it increased ranging from 285 to 810 c.c., and that the specific gravity which is generally high in this type showed no appre- 
TABLE I.

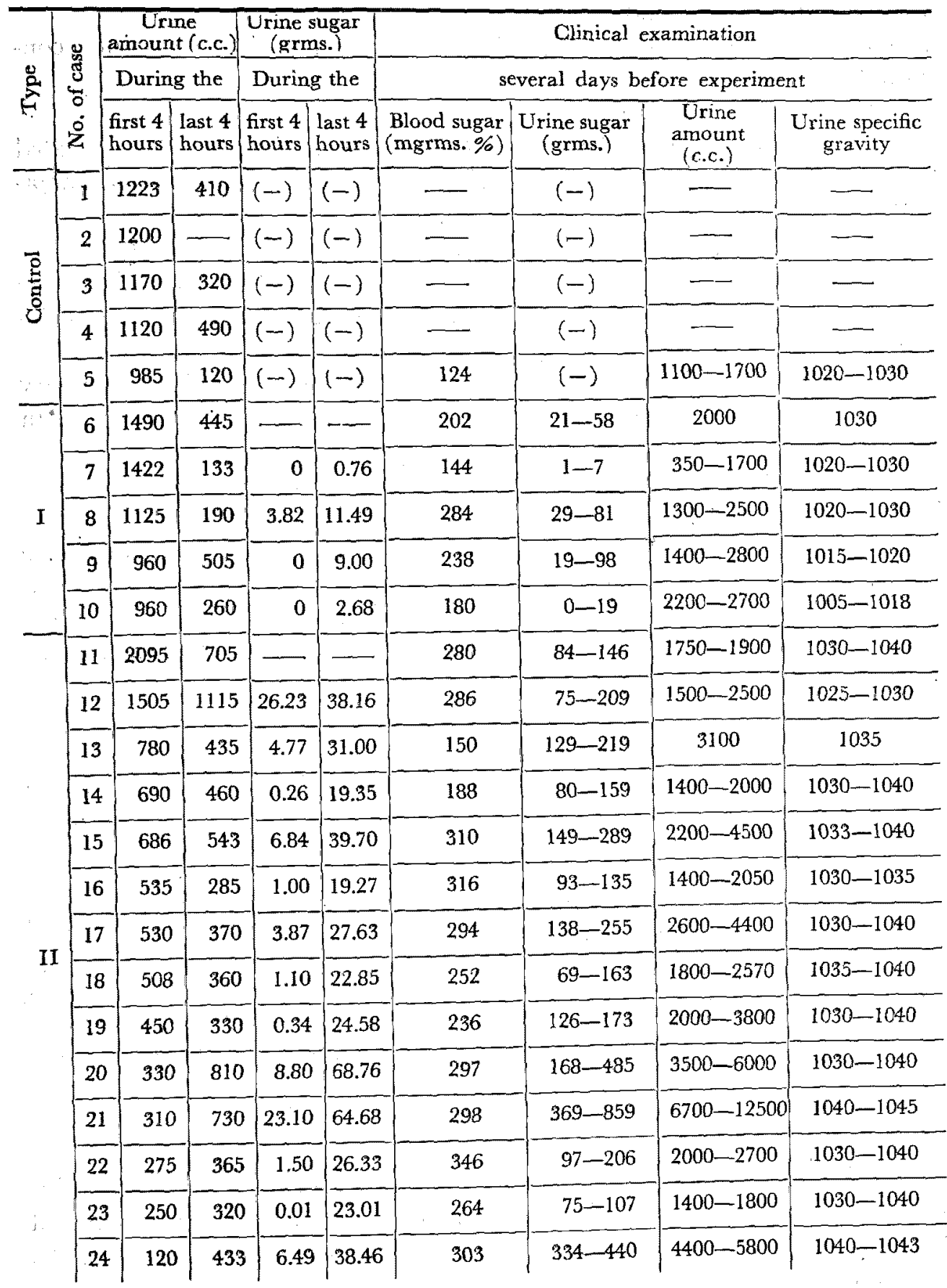

ciable fall after the administration of water and no remarkable rise after the intake of bread. 
It is a matter of course that the urine sugar was found in all cases during both the first and the last 4 hours.

Weight: 8 patients gained, 3 patients lost and 1 patient remained constant in weight.

After the treatment:

In about one half of these cases the same experiments were repeated in order to observe the influence of diabetic treatment on the water metabolism.

Results were indicated in Table II.

In Case 10 which received dietary treatment for 41 days, the urine output increased from 960 to 1275 c.c. during the first 4 hours and decreased in some degree during the last 4 hours.

In Case 13 which showed no remarkable effect in spite of dietary control for 13 days, a decreased urine output was observed during both the first and the last 4 hours, and the latter is especially striking.

In Case 14 which showed not only no disappearance of urine sugar but the rise of blood sugar with the use of insulin for 66 days, the urine output decreased during the first 4 hours and increased during the last 4 hours. On the contrary, in Cases 15, 22 and 24, in which we found a remarkable decrease of blood sugar and no urine sugar with insulin injec-: tion, there was a marked increase of urine output during the first 4 hours and decrease during the last 4 hours.

In Case 18, we found the same result as in previous 3 cases, with the exception of a slight increase during the latter.

In Case 20, we noticed no distinct contrast between the result of experiment before and after dietary treatment, and the same experiment without water which was repeated two days later indicated the same result as before contrary to our expectation.

From this fact, it is probable, that the administration of water has no influence upon the urine output.

While, in this case, after recovery with insulin treatment for 46 days with a marked decline of blood and urine sugar, we found an interesting fact that the amount of urine showed a conspicuous increase during the first and decrease during the last 4 hours.

In Case 21, the same result as in Case 20 was derived.

Blood sugar curve:

In 9 cases the blood and urine sugar were observed simultaneously; the gradual fall after the administration of water and rise after that of bread were found, and the severer diabetes were, the more remarkable the results were. 
TABLE II.

\begin{tabular}{|c|c|c|c|c|c|c|c|c|c|c|}
\hline \multirow{3}{*}{$\sum_{k}^{2}$} & \multirow{3}{*}{ 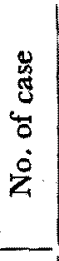 } & \multirow{2}{*}{ emarks } & \multicolumn{2}{|c|}{$\begin{array}{c}\text { Urine } \\
\text { amount (c.c.: }\end{array}$} & \multicolumn{2}{|c|}{$\begin{array}{c}\text { Urine sugar } \\
\text { (grms.) }\end{array}$} & \multicolumn{4}{|c|}{ Clinical examination } \\
\hline & & & \multicolumn{2}{|c|}{ During the } & \multicolumn{2}{|c|}{ During the } & \multicolumn{4}{|c|}{ several days before experiment } \\
\hline & & After giving & $\begin{array}{l}\text { first } 4 \\
\text { hours }\end{array}$ & $\begin{array}{l}\text { last } 4 \\
\text { hours }\end{array}$ & $\begin{array}{l}\text { first } 4 \\
\text { hours }\end{array}$ & $\begin{array}{l}\text { last } 4 \\
\text { hours }\end{array}$ & $\begin{array}{c}\text { Blood } \\
\text { sugar } \\
\text { (mgrms. } \\
\% \text { ) }\end{array}$ & $\begin{array}{c}\text { Urine } \\
\text { sugar } \\
\text { (grms.) }\end{array}$ & $\begin{array}{l}\text { Urine } \\
\text { amount } \\
\text { (c.c.) }\end{array}$ & $\begin{array}{l}\text { Urine } \\
\text { specific } \\
\text { gravity }\end{array}$ \\
\hline \multirow[t]{2}{*}{ I } & \multirow[t]{2}{*}{10} & S.d. for 8 days & 960 & 260 & 0 & 2.68 & 180 & $0-19$ & \multicolumn{2}{|c|}{$2200-2700 \quad 1005-1018$} \\
\hline & & S.d. for & 1275 & 210 & $\underline{0}$ & 0 & 172 & $(-1)$ & \multicolumn{2}{|c|}{$1900-31001015-1020$} \\
\hline \multirow{2}{*}{\multicolumn{2}{|c|}{13}} & $\mathbf{F}$ & 780 & 435 & 4.77 & 31.00 & 150 & $129-219$ & 3100 & 1035 \\
\hline & & S.d. $\mathrm{f}$ & 690 & 255 & 0.07 & 14.27 & 174 & $106-152$ & $2000-2400$ & $1035-1040$ \\
\hline \multirow{2}{*}{\multicolumn{2}{|c|}{14}} & S.d. for 7 days & 690 & 460 & 0.26 & 19.35 & 188 & $80-159$ & $1400-2000$ & 1030 \\
\hline & & Ins. for 66 days & 470 & 745 & $(+)$ & $(+)$ & 282 & $26-61$ & $1100-1500$ & $1020-1030$ \\
\hline \multirow{2}{*}{\multicolumn{2}{|c|}{5}} & S.d.for 7 days & 680 & 543 & 6.84 & 39.70 & 310 & $149-289$ & $2200-4500$ & $1033-1040$ \\
\hline & & Ins. for 33 days & 1358 & 74 & 0 & 0 & 124 & $(-) 1$ & $1900-2400$ & $1015-1025$ \\
\hline & \multirow[t]{2}{*}{18} & S.d. for 19 days & 508 & 360 & 1.10 & 22.85 & 252 & $69-163$ & $1800-2570$ & $1035-1040$ \\
\hline & & Ins. for 13 days & 858 & 420 & 3.41 & 9.35 & 184 & $0-301$ & $1300-2200$ & $1020-1030$ \\
\hline \multirow{4}{*}{\multicolumn{2}{|c|}{ II }} & et & 330 & 810 & 8.80 & 68.76 & 297 & $168-4853$ & $3500-6000$ & 1030 \\
\hline & & S.d. fo & 143 & 680 & 4.58 & 55.16 & 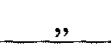 & & $2000-3$ & $1015-104$ \\
\hline & & $\begin{array}{r}\text { S,d. for } 7 \\
\text { (without g } \\
\text { water } \\
\end{array}$ & 5 & 600 & 6.93 & 55.08 & $"$ & " & $"$ & " \\
\hline & & Ins. for 4 & 1040 & 148 & 0 & .50 & 111 & $0-3$ & $1000-3300$ & -1020 \\
\hline \multirow{4}{*}{\multicolumn{2}{|c|}{21}} & Full d & 310 & 730 & 23.10 & 64.68 & 298 & $369-859$ & $6700-12500$ & $1040-1045$ \\
\hline & & S.d. for 1 & 180 & 605 & 3.57 & 47.59 & 208 & $210-400$ & $3150-5800$ & \\
\hline & & $\begin{array}{c}\text { S.d. for } 10 \text { days } \\
\text { (without giving } \\
\text { water) }\end{array}$ & 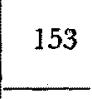 & 500 & 1.14 & 20.24 & $"$ & " & $"$ & " \\
\hline & & Ins. for 28 days & 1475 & 225 & 0 & 4.24 & 111 & $0-8$ & $1000-2000$ & $1010-1020$ \\
\hline \multirow{2}{*}{\multicolumn{2}{|c|}{22}} & Full diet & 275 & 365 & 1.50 & 26.33 & 346 & $97-206$ & $2000-2700$ & $1030-1040$ \\
\hline & & Ins. for 12 days & 1013 & 219 & $\underline{0}$ & 9.32 & 234 & $0-44$ & $740-1300$ & \\
\hline \multirow{3}{*}{\multicolumn{2}{|c|}{24}} & Full diet & 120 & 433 & 6.49 & 38.46 & 303 & $334-440$ & $4400-5800$ & $1040-1043$ \\
\hline & & S.d. for 14 days & 205 & 562 & 13.09 & 44.05 & $\mu$ & $157-254$ & $2100-3000$ & $1043-1047$ \\
\hline & & Ins. for 12 days & 1764 & 296 & 0 & 0 & , & $(-)$ & $600-1300$ & $1015-1030$ \\
\hline
\end{tabular}

S.d.: standard diet. Ins.: insulin.

\section{SUMMARY.}

\section{Dilution test:}

No remarkable difference between normal individuals and the patients of Type I was observed. The amount of urine output was approximately 1000 c.c., the specific gravity gradually decreased and the body weight was invariable or slightly lost. 
On the contrary, in Type II there were no striking increase of output and fall of specific gravity except 2 cases.

The results of the above experiment correspond to that of Klein, ${ }^{16)}$ Gerbi $^{19)}$ and Ralli. ${ }^{20)}$

Moreover, it is interesting that the same results were obtained in the experiment performed without giving water; and it is assumed that in severe cases of diabetes the water intake has no influence upon the urine output and the fluid taken is stored in the body.

After recovery from diabetic symptoms by the suitable treatment, the urine output increased in every case, especially remarkable in severe cases notwithstanding the total daily amount becoming small, although we found no great difference in comparison with the results before the treatment when there was no recovery.

Concentration test:

In every case the rise of specific gravity was observed, while in Type II it is so high previously as a rule that it was not so marked.

The amount of urine is comparatively small in Type I.

As Kailhack ${ }^{21)}$ described, we found out a close relation between the amount of urine output and urine sugar, that is, when the former was large the latter was simillarly large and we noticed the decrease of the former together with that of the latter after recovery with the diabetic treatment.

Discussion:

As many authors stated, no established theory on the disturbance of water metabolism has been found.

They thought to find out the causal meaning in the disturbances of kidney function caused by glycosuria, ${ }^{22}$ in diabetic acidosis, ${ }^{3) 6}$ in the failure of the intermediary water metabolism in the tissues, ${ }^{15}$ ) in saline action; ${ }^{23)}$ in the insufficiency of nutrition of capillary wall due to the disturbance of carbohydrate assimilating process ${ }^{7}$ and in hypophysis. ${ }^{24}$

In severe stage of diabetes, there occurs the profound dehydration from the excessive loss of water, and it is easily assumed that in the dilution test done under this condition the administrated water is stored in the body, and that by the administration of bread this stored fluid is excreted in a large quantity of urine which goes in parallel with the rise of blood sugar and the increase of urine sugar.

After all, severe diabetic patients have a tendency to store the fluid in the body cells preparing for excretion of an increased urine sugar following hyperglycemia.

If they take the food which causes hyperglycemia without taking the water sufficiently, the occurence of dehydration, clinically thirst and desiccation of the skin are observed. 
On the contrary if they take the water sufficiently and the food restrictedly, the fluid is stored and clinically edema occurs.

In severe diabetic cases, as Nakagawa ${ }^{9 !}$ reported, it is easily understood that we see frequently the occurence of edema in such cases as the restricted diet is given; while Stolte ${ }^{8)}$ said diabetic edema is due to cachexia caused by the excessive limitted diet, therefore, the food must be given sufficiently; although this is different from our opinion theoretically, we can easily endorse it.

Further, it is understood from these facts that it is seldom to seediabetic edema under the dietary management of our Clinic, containing 250350 grms. of carbohydrate, $80-100$ grms. of protein, $30-40$ grms. of fat and about 1600-2200 calories.

\section{Conclusions.}

1. Concerning the dilution test which is done with normal persons and diabetic patients of Type $I$, there is no striking difference between them; on the contrary, in Type II, the amount of urine is very small.

2. After recovery from diabetic symptoms, it increases in every case, especially remarkable in severe cases in spite of the disappearance of polyuria.

3. In the concentration test, we find a parallel relation between the amount of urine and urine sugar.

4. In severe cases there is a tendency to store the water in the body preparing for excretion of an increased urine sugar following hyperglycemia. It is probable that when they take such food as causes hyperglycemia without taking the water sufficiently, clinically a severe degree of thirst and desiccation of the skin occur, on the contrary, when they take the water sufficiently and the food restrictedly, the fluid is stored in the body cells and edema occurs.

\section{References.}

(1) Jaksch, R. v.: Z. klin. Med., 1893, 23, 187.

(2) Klein, O.: Ibid., 1924, 100, 458.

(3) Hoff, F.: Dtsch. med. Wschr., 1935, 741 and 789.

(4) Naunyn, B.: Nothnagel's Spezielle Pathologie und Therapie, VII. Band, VI. Theil, Diabetes mellitus, Wien 1898, 212.

(5) Ebstein, W.: Z. klin. Med., 1900, 40, 181.

(6) Földes, E.: Wien. Arch. inn. Med., 1922, 3, 469.

(7) Falta, W.: Ibid., 1923, 5, 581.

(8) Stolte, K.: Med. Klin., 1933, 999.

(9) Nakagawa, K.: Nippon Iji Shimpo, 1941, No. 1002, 33.

(10) Mirowsky, M.: Dtsch. med. Wschr., 1912, 459.

(11) Kylin, E.: Z. exper. Med., 1928, 63, 606. 
(12) Taterka, H.: Klin. Wschr,, 1929, 1763.

(13) Wiechmann, E. and S. Liaug: Dtsch. Arch. klin. Med., 1929, 163, 282.

(14) Goldberger, B. a. J.: Klin. Wschr., 1930, 1249.

(15) Meyer-Bisch, R.: Ergeb. inn. Med., 1927, 32, 267.

(16) Klein, O.: Z. exper. Med., 1925, 47, 309.

(17) Winter, F.: Acta med. scand., 1933, 80, 136.

(18) Takeda, S.: Insulin treatment in diabetes and non-diabetes, Tokyo 1927, 42.

(19) Gerbi, C.: Kongr. zbl. inn. Med., 1933, 68, 274.

(20) Ralli, E. P., A. M. Waterhouse and O. Rheinhart: Amer. J. med. Sci., 1934, 187, 607.

(21) Keilhack, H.: Z. exper. Med., 1933, 89, 159.

(22) v. Noorden, C.: Zuckerkrankheit, 6te Aufl. Berilin 1912, 128.

(23) Lichtwitz, L.: Mohr-Staehelin's Handbuch der inneren Med., 2te Aufl. VI. Band, I Teil, Stoffwechselerkrankungen, Berlin 1926, 752.

(24) Wada, H.: Nippon Iji Shimpo, 1936, No. 718, 2068. 